\title{
Conventional Vickers and true instrumented indentation hardness determined by instrumented indentation tests
}

\author{
Seung-Kyun Kang \\ Department of Materials Science and Engineering, Seoul National University, Seoul 151-744, Korea \\ Ju-Young Kim ${ }^{\text {a) }}$ \\ Materials Science, California Institute of Technology, Pasadena, California 91106 \\ Chan-Pyoung Park, Hyun-Uk Kim, and Dongil Kwon \\ Department of Materials Science and Engineering, Seoul National University, Seoul 151-744, Korea
}

(Received 16 September 2009; accepted 18 November 2009)

\begin{abstract}
We evaluate Vickers hardness and true instrumented indentation test (IIT) hardness of 24 metals over a wide range of mechanical properties using just IIT parameters by taking into account the real contact morphology beneath the Vickers indenter. Correlating the conventional Vickers hardness, indentation contact morphology, and IIT parameters for the 24 metals reveals relationships between contact depths and apparent material properties. We report the conventional Vickers and true IIT hardnesses measured only from IIT contact depths; these agree well with directly measured hardnesses within $\pm 6 \%$ for Vickers hardness and $\pm 10 \%$ for true IIT hardness.
\end{abstract}

\section{INTRODUCTION}

The fundamental advantage of instrumented indentation testing (IIT) over conventional hardness testing is that mechanical properties such as elastic modulus, ${ }^{1-15}$ tensile properties, ${ }^{16-29}$ and hardness can be measured by analyzing the indentation force-depth curve and without observing the residual indentation marks. However, elastoplastic deformation of materials around the indenter, i.e., plastic pileup or sink-in, ${ }^{30-37}$ makes it difficult to determine the true contact depth in the loaded state. A contact depth can be determined by taking into account the response of two major materials to an indentation, elastic deflection from the initial sample surface, and plastic pileup/sink-in around the indenter. ${ }^{30-37}$ The elastic deflection depth $\left(h_{\mathrm{d}}\right)$ is given by the widely used Oliver and Pharr method ${ }^{3,12}$ :

$$
h_{\mathrm{d}}=\varepsilon \frac{P_{\max }}{S},
$$

where $P_{\max }$ and $S$ are the maximum indentation force and initial unloading stiffness, respectively, and $\varepsilon$ is a geometrical constant ( 0.75 for a conical indenter). However, the plastic pileup and sink-in cannot be expressed as an analytical equation because the plastic deformation underneath the indenter is far more complex than elastic deflection.

Many studies ${ }^{30-37}$ have been performed to evaluate the contact depth, taking into account the plastic pileup/

\footnotetext{
a) Address all correspondence to this author.

e-mail: juyoung1@snu.ac.kr

DOI: $10.1557 / J M R .2010 .0045$
}

sink-in of a sharp indenter. From extensive finiteelement analysis (FEA) work on a wide range of elastoplastic materials, Cheng and Cheng ${ }^{13,25,30}$ proposed to measure elastic modulus and hardness without determining the contact area directly by correlating these properties and the indentation work ratio. Alcala et al., ${ }^{35}$ using FEA, suggested a relationship between strain-hardening exponent $n$ and pileup/sink-in height. Cheng and Cheng also suggested a correction parameter $f$, the ratio of contact depth $\left(h_{\mathrm{c}}\right)$ to maximum indentation depth $\left(h_{\max }\right)$, and showed that $f$ is given by the product of a function of the strain-hardening exponent $n$ and the ratio of yield strength to reduced elastic modulus $\left(\sigma_{\mathrm{ys}} / E_{\mathrm{r}}\right) .{ }^{31,32}$ Choi et al. ${ }^{36}$ proposed a modified correction parameter $f$ including indenter tip bluntness $\left(\Delta h_{\mathrm{b}}\right)$ as:

$$
f=\frac{h_{\mathrm{c}}}{h_{\max }+\Delta h_{\mathrm{b}}}=1.2445(1-0.6 n)\left(1-7.2 \frac{\sigma_{\mathrm{ys}}}{E_{\mathrm{r}}}\right) \text {. }
$$

However, previous research on this topic has all or some of the following limitations that require further studies:

(i) The data were obtained by FEA simulation. Even though FEA is a well-established tool, more real data are certain to be obtained by experimental results.

(ii) In the FEA simulations, conical indenters were used to simulate sharp indenters such as Berkovich and Vickers indenters. While this difference does not matter for true IIT hardness, it is critical when conventional Vickers hardness is measured by IIT, since it depends only on contact depth at corners. 
(iii) To use the proposed equations, tensile properties such as strain-hardening exponent and yield strength are required. Since the proposed equations cannot be applied only with IIT for unknown materials, their applications are limited.

To explain the three different hardness values and corresponding contact depths in IIT using a Vickers indenter, we show in Fig. 1 a schematic of contact morphology for pileup around a Vickers indenter. First, conventional IIT hardness $\left(H_{\mathrm{O}-\mathrm{P}}\right)$ is given by the maximum indentation force divided by the projected contact area corresponding to the contact depth $\left(h_{\mathrm{c}, \mathrm{O}-\mathrm{P}}\right)$ in the Oliver-Pharr method ${ }^{3,12,38}$ :

$$
H_{\mathrm{O}-\mathrm{P}}=\frac{P_{\max }}{24.5 \times\left(h_{\mathrm{c}, \mathrm{O}-\mathrm{P})^{2}}\right.},
$$

which subtracts the elastic deflection depth $h_{\mathrm{d}}$ from the maximum indentation depth $h_{\max }$. This hardness is measured only with IIT parameters such as maximum applied force and unloading stiffness, as shown in Eq. (1), and thus is widely used although it does not take into account plastic pileup/sink-in. Second, true IIT hardness $\left(H_{\text {true }}\right)$ is given by the maximum force divided by the true projected contact area $\left(h_{\mathrm{c}}^{\text {pro }}\right)$ :

$$
H_{\text {true }}=\frac{P_{\max }}{24.5 \times\left(h_{\mathrm{c}}^{\text {pro }}\right)^{2}},
$$

considering plastic pileup/sink-in. Since plastic pileup/ sink-in is more constrained at the corners of the Vickers

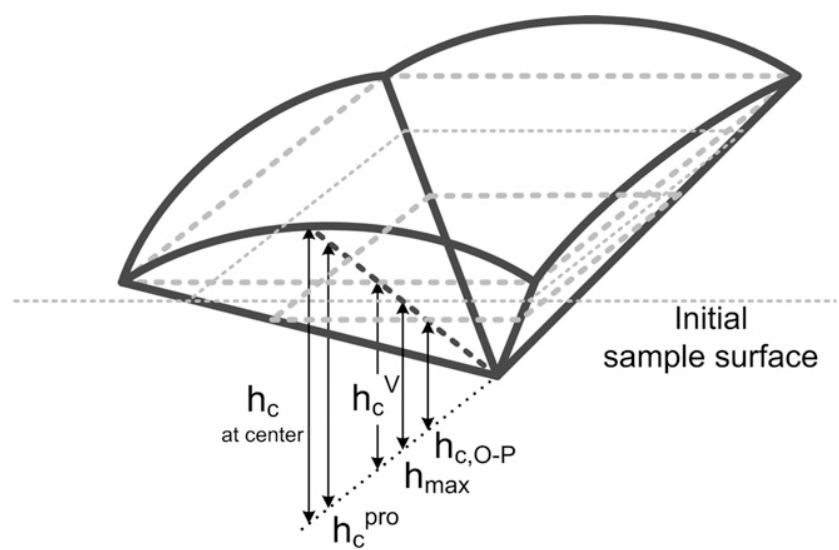

(a)

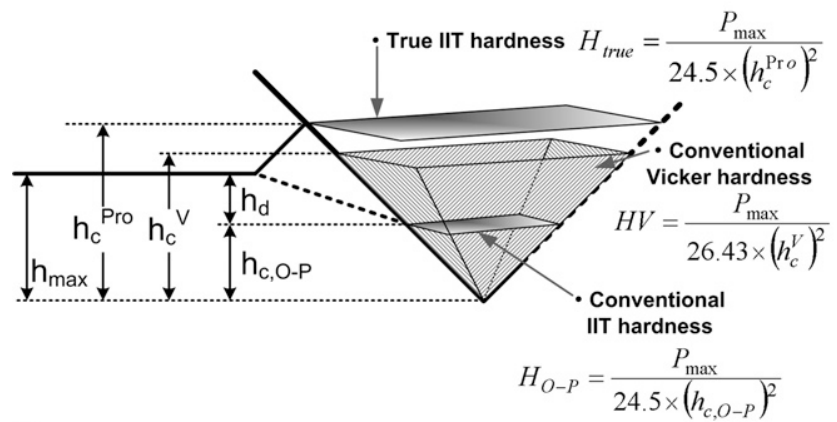

(b)

FIG. 1. Diagonal area and projected area at pileup and sink-in. indenter, the projected contact depth representing the projected contact area may lie between the contact depths at the center and at a corner. Third, the conventional Vickers hardness is given by the maximum force divided by the four-sided pyramidal contact area, which is evaluated from the diagonals of the residual indentation marks after unloading. If the recovery in the inplane direction during unloading is negligible ${ }^{35}$ the diagonals evaluated from the contact depth at corners in the loaded state $\left(h_{\mathrm{c}}^{\mathrm{V}}\right)$ should be the same as those of the residual indentation marks. Vickers hardness is represented by contact depth at corners as

$$
H V=\frac{P_{\text {max }}}{26.43 \times\left(h_{\mathrm{c}}^{\mathrm{V}}\right)^{2}} \quad .
$$

Vickers hardness, the result of conventional hardness testing using a self-similar indenter, is widely used and has an extensive number of databases. Nevertheless, the evaluation algorithms for Vickers hardness using IIT are insufficient for its industrial uses. The problem arises from the different definitions of contact area in Vickers hardness and IIT hardness. Vickers hardness calculates the contact area from the corner-to-corner diagonal, ignoring the difference in pileup/sink-in around the side of indenter, which must be contained to derive the IIT hardness. Thus, algorithms for evaluating not only true IIT hardness but also Vickers hardness that take into account the real contact depth through IIT will be simple and useful techniques in hardness testing.

In this study, we propose methods for measuring Vickers hardness and true IIT hardness that use IIT alone by taking into account the pileup height at the corner and the representative pileup height, respectively. To this end, we correlate the pileup heights with experimentally measured IIT parameters for 24 metals over a wide range of mechanical properties. We show that the true IIT hardness and conventional Vickers hardness measured by the proposed methods for the 24 metals agree well with the true values within $\pm 6 \%$ for Vickers hardness and $\pm 10 \%$ for true IIT hardness.

\section{EXPERIMENTS}

Twenty-four metal samples with a wide range of mechanical properties- $\mathrm{Al}$ alloys, $\mathrm{Mg}$ alloys, $\mathrm{Cu}$ alloys, $\mathrm{Ti}$ alloys, Ni alloys, carbon steels, API X-grade steels, ferrite-based stainless steels, and austenite-based stainless steels-were prepared for indentation tests and uniaxial tensile tests. For the indentation tests, one side of the samples was finely polished with $1 \mu \mathrm{m}$ alumina powder. IITs were conducted using the AIS 3000 instrumented indentation system (Frontics Inc., Seoul, Korea) with force resolution of $55 \mathrm{mN}$ and displacement resolution of $100 \mathrm{~nm}$ and a Vickers indenter. The IITs were 
performed at constant displacement rate $0.3 \mathrm{~mm} / \mathrm{min}$ with maximum indentation depth of $80 \mu \mathrm{m}$. After indentation, the residual indentation marks were observed by optical microscopy to evaluate the conventional Vickers hardness. The relationship between the diagonal and contact depth at the corner of the residual indent is given by

$$
h_{\mathrm{c}}^{\mathrm{V}}=\frac{d}{2 \sqrt{2} \tan \theta_{\mathrm{V}}},
$$

where $\theta_{\mathrm{V}}$ is the half angle of the Vickers indenter, $68^{\circ}$. The ratio of contact depth at the corner to maximum indentation depth is defined as

$$
f_{\mathrm{V}}=\frac{h_{\mathrm{c}}^{\mathrm{V}}}{h_{\max }}
$$

Because the elastic recovery during unloading happens mainly along loading direction and negligible in-plane direction, ${ }^{35}$ the projected contact area at the maximum indentation depth can be measured directly from the area of the residual indentation mark. The projected area $A_{\mathrm{c}}^{\text {pro }}$ was measured using an image analyzer (NIS Elements, Nikon, Tokyo, Japan), from which the projected contact depth $h_{\mathrm{c}}^{\text {pro }}$ was calculated by

$$
h_{\mathrm{c}}^{\mathrm{pro}}=\frac{\sqrt{A_{\mathrm{c}}^{\mathrm{pro}}}}{2 \tan \theta_{\mathrm{V}}},
$$

and the ratio of the projected contact depth to maximum indentation depth is defined as

$$
f_{\text {pro }}=\frac{h_{\mathrm{c}}^{\text {pro }}}{h_{\max }} .
$$

Figure 1 shows the contact morphology of Vickers indentation for material pileup around the indenter. The contact depth at the corner $h_{\mathrm{c}}^{\mathrm{V}}$ determines conventional Vickers hardness, while the projected contact depth $h_{\mathrm{c}}^{\text {pro }}$ is the parameter determining the true IIT hardness.

Uniaxial tensile tests were carried out using an Instron 5582 (Instron Inc., Grove City, PA) at cross-head speed $1 \mathrm{~mm} / \mathrm{min}$; the gauge length and diameter of the cylindrical specimens were 25 and $6 \mathrm{~mm}$, respectively, in accordance with the ASTM standard. ${ }^{39}$ Elastic moduli of the samples were measured by an ultrasonic pulseecho technique using a two-channel digital real-time oscilloscope.

\section{RESULTS AND DISCUSSION}

To explore the relationship between plastic pileup underneath the Vickers indenter and material plastic properties, we show in Fig. 2 the relationship of the contact depth function $f_{\mathrm{V}}$ versus the strain-hardening exponent $n$ and the ratio of elastic modulus to yield strength, $E / \sigma_{\mathrm{ys}}$, corresponding to the inverse of the yield strain, both of which have been widely used to describe plastic indentation pileup. ${ }^{31,32,35,36}$ For the metal samples, $f_{\mathrm{V}}$ shows good linearity with $E / \sigma_{\mathrm{ys}}$, while it has much less relation with $n$. If we assume a Tabor relationship between yield strength and hardness $\left(H=\Psi \sigma_{\mathrm{ys}}\right.$, where $\Psi$ is plastic constraint factor of 3$),{ }^{9} f_{\mathrm{V}}$ can also be related to $E / H$, as shown in Fig. 3. It is notable that, in Fig. 3, hardness $H$ and elastic modulus $E$ are determined by optically measured projected area of residual impression and ultrasonic pulse-echo technique, respectively, not by the $E / \sigma_{\mathrm{y}}$ data in Fig. 2. The ratio of hardness

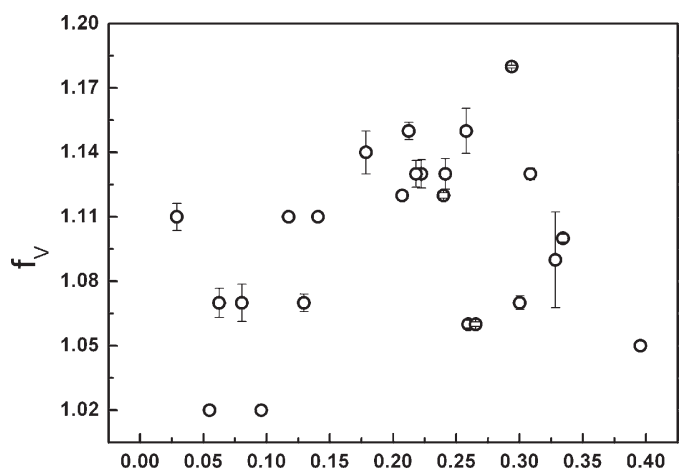

(a)

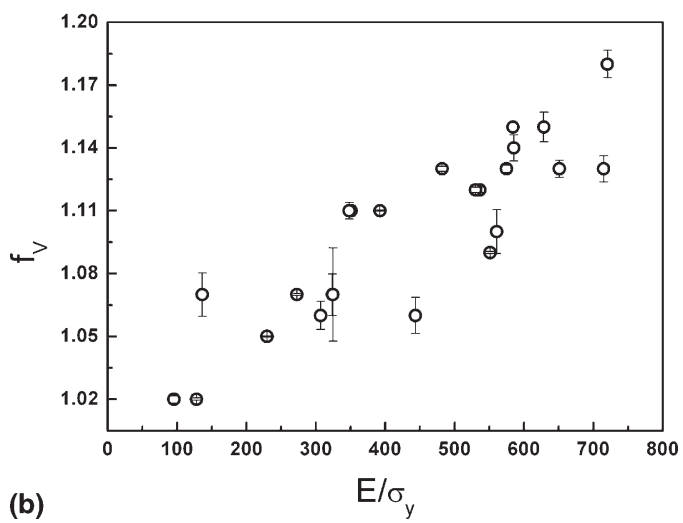

FIG. 2. Relation between contact depth function and tensile properties. (a) Hardening exponent and (b) ratio of elastic modulus and yield strength.

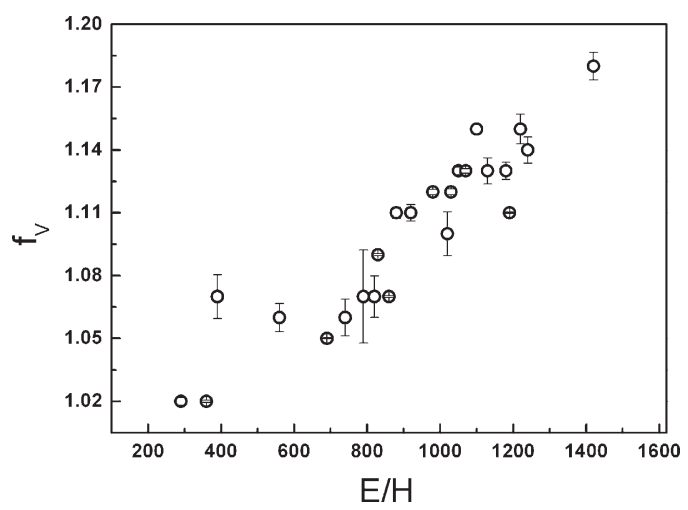

FIG. 3. Relation between contact depth function and ratio of elastic modulus and hardness. 
and elastic modulus can be expressed as the ratio of irreversible work $\left(W_{\text {total }}-W_{\mathrm{e}}\right)$ to total work $\left(W_{\text {total }}\right)$ during indentation:

$$
1-k \frac{H}{E}=\frac{W_{\text {total }}-W_{\mathrm{e}}}{W_{\text {total }}}
$$

where $W_{\mathrm{e}}$ is the work recovered during unloading and $k$ is a constant commonly taken as $5{ }^{36}$ By using linear indentation loading and unloading curves, $W_{\text {total }}$ and $W_{\mathrm{e}}$ are measured approximately by

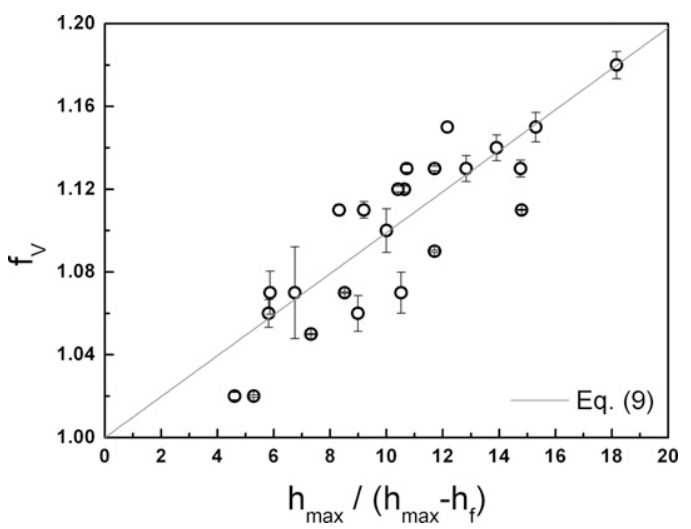

FIG. 4. Linear relation of contact depth function at corner and normalized recovery depth.

$$
k \frac{H}{E}=\frac{W_{\mathrm{e}}}{W_{\text {total }}} \approx \frac{h_{\max }-h_{\mathrm{f}}}{h_{\max }}
$$

The ratio of elastic modulus to yield strength can thus be represented using Eqs. (10) and (11) by the maximum indentation depth $h_{\max }$ and final indentation depth $h_{\mathrm{f}}{ }^{12,36}$

Figure 4 shows the relationship between the contact depth function $\left(f_{\mathrm{V}}\right)$ and contact depth ratio $h_{\max } /$ $\left(h_{\max }-h_{\mathrm{f}}\right)$, which shows good linearity; we obtain the linear relation

$$
f_{\mathrm{V}}=9.90 \times 10^{-3} \frac{h_{\max }}{h_{\max }-h_{\mathrm{f}}}+1.00
$$

which can be written as

$$
\frac{h_{\mathrm{c}}^{\mathrm{V}}-h_{\max }}{h_{\max }}=9.90 \times 10^{-3}\left(\frac{h_{\max }-h_{\mathrm{f}}}{h_{\max }}\right)^{-1},
$$

where $\left(h_{\mathrm{c}}^{\mathrm{V}}-h_{\max }\right) / h_{\max }$ is the normalized pileup from the reference plane, and $\left(h_{\max }-h_{\mathrm{f}}\right) / h_{\max }$ is the normalized recovery depth. For a geometrically selfsimilar sharp indenter such as the Vickers indenter, the representative total strain is determined regardless of indentation depth, ${ }^{9,13}$ so the plastic pileup is most

\begin{tabular}{|c|c|c|c|c|c|c|c|c|c|}
\hline & Materials & $E / \sigma_{\mathrm{ys}}$ & $n$ & $\begin{array}{c}h_{\mathrm{c}}^{\mathrm{V}} \\
(\mu \mathrm{m})\end{array}$ & $\begin{array}{l}h_{\mathrm{c}}^{\mathrm{V}} \text { Eq. }(12) \\
(\mu \mathrm{m})\end{array}$ & $\begin{array}{c}\text { Error } \\
(\%)\end{array}$ & $\begin{array}{l}\text { Vickers hardness } \\
(\mathrm{HV})\end{array}$ & $\begin{array}{l}\text { Vickers hardness } \\
\text { Eq. (12) (HV) }\end{array}$ & $\begin{array}{l}\text { Error } \\
(\%)\end{array}$ \\
\hline \multirow[t]{2}{*}{$\mathrm{Al}$ alloy } & Al6061 & 323.86 & 0.063 & 84.95 & 87.81 & 3.4 & 117.38 & 109.85 & -6.4 \\
\hline & $\mathrm{Al} 7075$ & 136.19 & 0.080 & 84.77 & 83.76 & -1.2 & 173.47 & 177.71 & 2.4 \\
\hline \multirow[t]{2}{*}{$\mathrm{Mg}$ alloy } & AZ61 & 272.73 & 0.300 & 85.52 & 86.53 & 1.2 & 44.94 & 43.90 & -2.3 \\
\hline & AZ910 & 229.59 & 0.396 & 83.49 & 85.48 & 2.4 & 58.44 & 55.75 & -4.6 \\
\hline \multirow[t]{3}{*}{$\mathrm{Cu}$ alloy } & $\mathrm{C} 1010$ & 392.46 & 0.029 & 88.26 & 91.24 & 3.4 & 80.30 & 75.14 & -6.4 \\
\hline & C5101 & 551.17 & 0.328 & 86.52 & 88.85 & 2.7 & 85.66 & 81.22 & -5.2 \\
\hline & C62400 & 307.01 & 0.259 & 83.61 & 83.48 & -0.2 & 212.68 & 213.36 & 0.3 \\
\hline \multirow[t]{2}{*}{ Ti alloy } & $\begin{array}{l}\mathrm{Ti}-10 \mathrm{~V}- \\
2 \mathrm{Fe}-3 \mathrm{Al}\end{array}$ & 95.36 & 0.096 & 79.85 & 82.15 & 2.9 & 360.48 & 340.65 & -5.5 \\
\hline & $\mathrm{Ti}-7 \mathrm{Al}-4 \mathrm{Mo}$ & 128.18 & 0.055 & 80.32 & 82.70 & 3.0 & 341.86 & 322.40 & -5.7 \\
\hline Ni alloy & Inconel 600 & 443.53 & 0.265 & 83.54 & 85.86 & 2.8 & 228.10 & 215.96 & -5.3 \\
\hline \multirow[t]{6}{*}{ Carbon steel } & $\mathrm{S} 45 \mathrm{C}$ & 584.15 & 0.258 & 90.71 & 88.67 & -2.2 & 181.61 & 190.06 & 4.7 \\
\hline & SCM21 & 714.93 & 0.222 & 90.03 & 89.40 & -0.7 & 160.11 & 162.36 & 1.4 \\
\hline & SCM4 & 324.59 & 0.130 & 83.78 & 83.81 & 0.0 & 285.95 & 285.78 & -0.1 \\
\hline & SKD61 & 574.92 & 0.241 & 89.62 & 87.55 & -2.3 & 189.86 & 198.96 & 4.8 \\
\hline & SKS3 & 481.92 & 0.218 & 89.78 & 88.38 & -1.6 & 182.22 & 188.03 & 3.2 \\
\hline & SUJ2 & 536.61 & 0.240 & 88.71 & 87.43 & -1.4 & 195.36 & 201.12 & 2.9 \\
\hline \multirow[t]{2}{*}{ API steel } & $\mathrm{X} 100$ & 350.84 & 0.141 & 87.85 & 85.30 & -2.9 & 240.19 & 254.77 & 6.1 \\
\hline & $\mathrm{X} 70$ & 348.16 & 0.117 & 87.37 & 86.18 & -1.4 & 216.69 & 222.68 & 2.8 \\
\hline \multirow{3}{*}{$\begin{array}{l}\text { Ferrite base } \\
\text { stainless steel }\end{array}$} & SUS303F & 560.65 & 0.334 & 87.40 & 87.37 & 0.0 & 175.06 & 175.18 & 0.1 \\
\hline & SUS310S & 720.29 & 0.294 & 93.86 & 93.89 & 0.0 & 129.46 & 129.36 & -0.1 \\
\hline & SUS316L & 651.07 & 0.309 & 89.77 & 91.18 & 1.6 & 158.28 & 153.40 & -3.1 \\
\hline \multirow{3}{*}{$\begin{array}{l}\text { Austenite base } \\
\text { stainless steel }\end{array}$} & SUS403 & 628.59 & 0.212 & 90.91 & 91.38 & 0.5 & 165.73 & 164.02 & -1.0 \\
\hline & SUS410 & 585.36 & 0.179 & 90.26 & 90.31 & 0.1 & 166.53 & 166.37 & -0.1 \\
\hline & SUS420J2 & 530.18 & 0.207 & 88.61 & 87.29 & -1.5 & 204.08 & 210.26 & 3.0 \\
\hline
\end{tabular}
likely to be related to the ratio of elastically recovered depth to maximum indentation depth. Table I presents

TABLE I. Evaluation of contact depth at the corner and Vickers hardness using the contact depth function. 
the corner contact depths and Vickers hardnesses directly measured from the profile of residual indentation marks and evaluated only from IIT parameters using Eqs. (6) and (12), respectively. The errors in contact depth and hardness are below $\pm 4 \%$ and $\pm 7 \%$, respectively.

True IIT hardness is given by the maximum applied load divided by the projected area in the loaded state, which can be work for elastoplastic deformation per unit volume and mean pressure. We directly compared the contact depth function for projected area $f_{\text {pro }}$ to

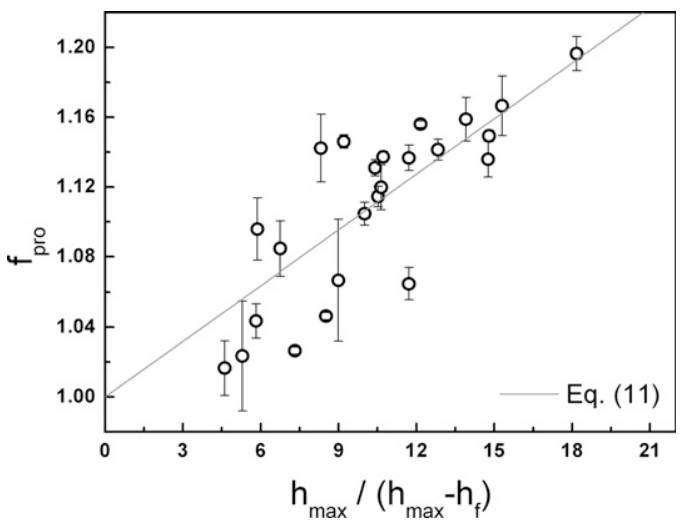

FIG. 5. Linear relation of contact depth function for projected area and normalized recovery depth. $h_{\max } /\left(h_{\max }-h_{\mathrm{f}}\right)$ and found a linear relation for the contact depth function at the corner; Fig. 5 shows the relation as

$$
f_{\text {pro }}=1.06 \times 10^{-2} \frac{h_{\max }}{h_{\max }-h_{\mathrm{f}}}+1.00 .
$$

Table II presents true IIT hardnesses directly measured from the profiles of residual indentation marks and evaluated only from IIT parameters using Eq. (14). These results imply that the true projected contact depth in the loaded state and true IIT hardness can be measured without additional observation of the residual impression and material properties. Figure 6 shows the relationship between two different contact areas: diagonal contact area $\left(A_{\text {dia }}\right)$ and projected contact area $\left(A_{\mathrm{c}}^{\text {pro }}\right)$ (see Fig. 7$) . A_{\mathrm{c}}^{\text {pro }}$ is $\sim 2 \%$ greater than $A_{\mathrm{c}}^{\text {dia }}$ :

$$
A_{\mathrm{c}}^{\text {pro }}=1.02 A_{\mathrm{c}}^{\mathrm{dia}} .
$$

Thus, when considering pileup dependent on indenter geometry as in Fig. 1, i.e., more pileup in the center and minimum pileup at each Vickers indenter corner, this result implies that the true contact area, which is the projected area at contact depth taking into account average pileup along the contact morphology, is slightly great than projected area at corner contact depth, $h_{\mathrm{c}}^{\mathrm{V}}$.

\begin{tabular}{|c|c|c|c|c|c|c|c|}
\hline & Materials & $h_{\mathrm{c}}^{\mathrm{pro}}(\mu \mathrm{m})$ & $\begin{array}{c}h_{\mathrm{c}}^{\text {pro }} \text { Eq. }(14) \\
(\mu \mathrm{m})\end{array}$ & Error $(\%)$ & $\begin{array}{c}\text { True IIT } \\
\text { hardness }(\mathrm{GPa})\end{array}$ & $\begin{array}{l}\text { True IIT hardness } \\
\text { Eq. (14) (GPa) }\end{array}$ & Error $(\%)$ \\
\hline \multirow[t]{2}{*}{$\mathrm{Al}$ alloy } & Al6061 & 88.63 & 88.40 & -0.3 & 1.14 & 1.15 & 0.5 \\
\hline & Al7075 & 86.75 & 84.08 & -3.1 & 1.75 & 1.86 & 6.4 \\
\hline \multirow[t]{2}{*}{ Mg alloy } & AZ61 & 83.49 & 87.01 & 4.2 & 0.50 & 0.46 & -7.9 \\
\hline & AZ910 & 81.82 & 85.89 & 5.0 & 0.64 & 0.58 & -9.3 \\
\hline \multirow[t]{3}{*}{$\mathrm{Cu}$ alloy } & $\mathrm{C} 1010$ & 91.45 & 92.06 & 0.7 & 0.79 & 0.78 & -1.3 \\
\hline & C5101 & 84.78 & 89.50 & 5.6 & 0.94 & 0.85 & -10.3 \\
\hline & C62400 & 82.37 & 83.80 & 1.7 & 2.32 & 2.24 & -3.4 \\
\hline \multirow[t]{2}{*}{ Ti alloy } & $\mathrm{Ti}-10 \mathrm{~V}-2 \mathrm{Fe}-3 \mathrm{Al}$ & 79.86 & 82.40 & 3.2 & 3.81 & 3.58 & -6.1 \\
\hline & Ti-7Al-4Mo & 80.43 & 82.99 & 3.2 & 3.60 & 3.38 & -6.1 \\
\hline $\mathrm{Ni}$ alloy & Inconel600 & 84.10 & 86.36 & 2.7 & 2.38 & 2.26 & -5.2 \\
\hline \multirow[t]{6}{*}{ Carbon steel } & $\mathrm{S} 45 \mathrm{C}$ & 91.49 & 89.34 & -2.3 & 1.89 & 1.98 & 4.9 \\
\hline & SCM21 & 90.53 & 90.11 & -0.5 & 1.67 & 1.69 & 0.9 \\
\hline & SCM4 & 85.21 & 84.18 & -1.2 & 2.92 & 2.99 & 2.5 \\
\hline & SKD61 & 90.02 & 88.14 & -2.1 & 1.99 & 2.08 & 4.3 \\
\hline & SKS3 & 90.02 & 89.03 & -1.1 & 1.92 & 1.96 & 2.2 \\
\hline & SUJ2 & 88.57 & 88.02 & -0.6 & 2.07 & 2.10 & 1.3 \\
\hline \multirow[t]{2}{*}{ API steel } & X100 & 90.02 & 85.76 & -4.7 & 2.42 & 2.66 & 10.2 \\
\hline & $\mathrm{X} 70$ & 90.52 & 86.69 & -4.2 & 2.13 & 2.33 & 9.0 \\
\hline \multirow{3}{*}{$\begin{array}{l}\text { Ferrite base } \\
\text { stainless steel }\end{array}$} & SUS303F & 87.82 & 87.93 & 0.1 & 1.83 & 1.83 & -0.3 \\
\hline & SUS310S & 95.21 & 94.91 & -0.3 & 1.33 & 1.34 & 0.6 \\
\hline & SUS316L & 90.36 & 92.01 & 1.8 & 1.65 & 1.59 & -3.5 \\
\hline \multirow{3}{*}{$\begin{array}{l}\text { Austenite base } \\
\text { stainless steel }\end{array}$} & SUS403 & 92.57 & 92.23 & -0.4 & 1.69 & 1.70 & 0.7 \\
\hline & SUS410 & 91.98 & 91.08 & -1.0 & 1.70 & 1.73 & 2.0 \\
\hline & SUS420J2 & 89.50 & 87.87 & -1.8 & 2.11 & 2.19 & 3.7 \\
\hline
\end{tabular}

TABLE II. Evaluation of projected contact depth and true IIT hardness using the contact depth function. 


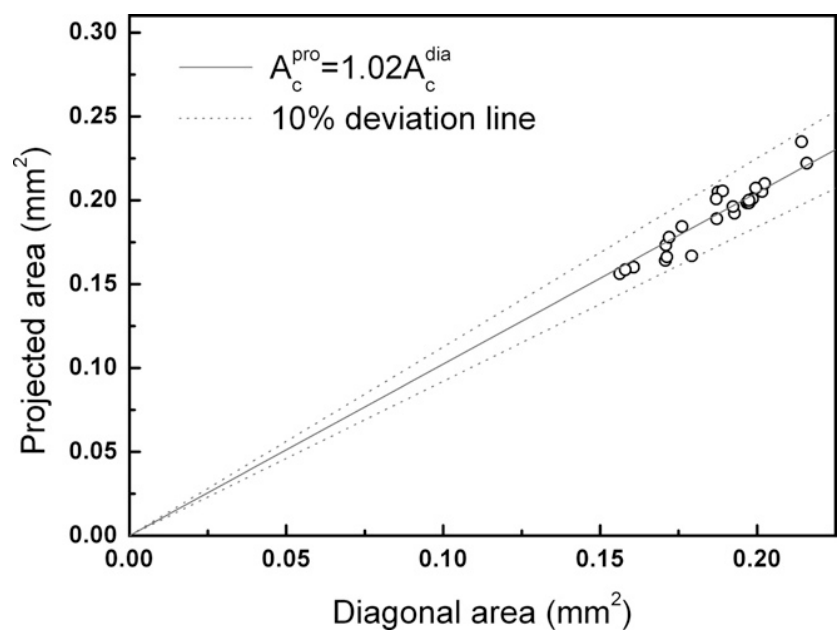

FIG. 6. Linear relation between projected area and diagonal area.
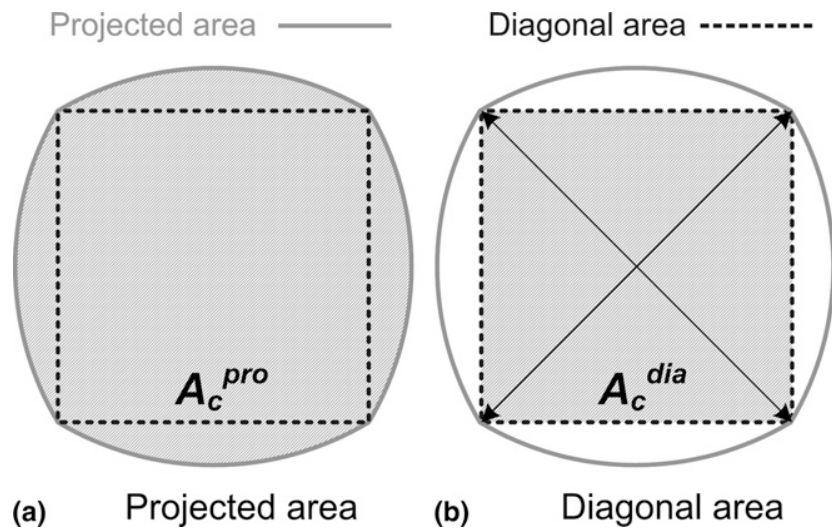

FIG. 7. Top view of the residual impression of Vickers indenter for (a) projected area and (b) diagonal area.

\section{CONCLUSIONS}

On the basis of experiments on the 24 metals, we found relations between the contact depth functions and indentation parameters that let us determine the Vickers hardness and true IIT hardness only with IIT. Using Eqs. (12) and (14) with only IIT parameters enabled us to obtain Vickers hardness and true IIT hardness within $\pm 6 \%$ and $\pm 10 \%$ error, respectively, of the directly measured values. Notable findings of this study are:

(1) The contact depth function correcting the pileup at corner of Vickers indenter is directly related to the ratio of yield strength to elastic modulus, rather than to the strain-hardening exponent.

(2) The ratio of yield strength to elastic modulus is represented by the ratio of recovered depth $\left(h_{\max }-h_{\mathrm{f}}\right)$ to maximum indentation depth $\left(h_{\max }\right)$, which is proportional to the inverse of the normalized pileup depth.

(3) Experimentally determined relationship between the contact depth functions $\left(f_{\mathrm{V}}, f_{\mathrm{pro}}\right)$ and the $\left(h_{\max }-h_{\mathrm{f}}\right) /$ $h_{\max }$ made it possible to evaluate the contact area and hardness using only IIT parameters.
(4) The projected area $A_{\text {pro }}$ has a linear relationship with the diagonal area $A_{\text {dia }}$ as in Eq. (15), suggesting that the average pileup height is slightly greater than that at the corners of the Vickers indenter.

\section{ACKNOWLEDGMENTS}

This research was supported in part by the Seoul R\&BD Program (Grant No. TR080564) of the Seoul Development Institute, Korea, and in part by the Improvement of Standardization Technology Program (Grant No. B0010740) of the Ministry of Knowledge Economy, Korea.

\section{REFERENCES}

1. S.I. Bulychev, V.P. Alekhin, M.K. Shorshorov, A.P. Ternovskii, and G.D. Shnyrev: Determining Young's modulus from the indentor penetration diagram. Zavod. Lab. 41, 1137 (1975).

2. M.F. Doerner and W.D. Nix: A method for interpreting the data from depth-sensing indentation instruments. J.Mater. Res. 1.601 (1986).

3. W.C. Oliver and G.M. Pharr: An improved technique for determining hardness and elastic-modulus using load and displacement sensing indentation experiments. J. Mater. Res. 7, 1564 (1992).

4. A. Gouldstone, N. Chollacoop, M. Dao, J. Li, A.M. Minor, and Y.L. Shen: Indentation across size scales and disciplines: Recent developments in experimentation and modeling. Acta Mater. 55. 4015 (2007).

5. A.C. Fischer-Cripps: A review of analysis methods for submicron indentation testing. Vacuum 58, 569 (2000).

6. N.K. Mukhopadhyay and P. Paufler: Micro- and nanoindentation techniques for mechanical characterisation of materials. Int. Mater. Rev. 51, 209 (2006).

7. J.S. Field and M.V. Swain: Determining the mechanical-properties of small volumes of material from submicrometer spherical indentations. J. Mater. Res. 10, 101 (1995).

8. C.A. Schuh: Nanoindentation studies of materials. Mater. Todav 9. 32 (2006).

9. D. Tabor: Hardness of Metals (Clarendon Press, Oxford, 1951).

10. A. Bolshakov and G.M. Pharr: Influences of pileup on the measurement of mechanical properties by load and depth-sensing indentation techniques. J. Mater. Res. 13, 1049 (1998).

11. A.C. Fischer-Cripps: Nanoindentation (Springer, New York, 2002).

12. W.C. Oliver and G.M. Pharr: Measurement of hardness and elastic modulus by instrumented indentation: Advances in understanding and refinements to methodology. J.Mater. Res. 19.3 (2004).

13. Y.T. Cheng and C.M. Cheng: Scaling, dimensional analysis, and indentation measurements. Mater. Sci. Eng., R 44, 91 (2004).

14. J.Y. Kim, S.K. Kang, J.R. Greer, and D. Kwon: Evaluating plastic flow properties by characterizing indentation size effect using a sharp indenter. Acta Mater. 56, 3338 (2008).

15. J.Y. Kim, S.K. Kang, J.J. Lee, J.I. Jang, Y.H. Lee, and D. Kwon: Influence of surface-roughness on indentation size effect. Acta Mater. 55, 3555 (2007).

16. J.H. Ahn and D. Kwon: Derivation of plastic stress-strain relationship from ball indentations: Examination of strain definition and pileup effect. J.Mater. Res. 16, 3170 (2001).

17. S.H. Kim, B.W. Lee, Y. Choi, D. Kwon: Quantitative determination of contact depth during spherical indentation of metallic materials-A FEM study. Mater. Sci. Eng., A 415, 59 (2006). 
18. J.Y. Kim, K.W. Lee, J.S. Lee, and D. Kwon: Determination of tensile properties by instrumented indentation technique: Representative stress and strain approach. Surf. Coat. Technol. 201. $4278(2006)$.

19. E.C. Jeon, J.Y. Kim, M.K. Baik, S.H. Kim, J.S. Park, D. Kwon: Optimum definition of true strain beneath a spherical indenter for deriving indentation flow curves. Mater. Sci. Eng., A 419, 196 (2006).

20. B. Taljat, T. Zacharia, and F. Kosel: New analytical procedure to determine stress-strain curve from spherical indentation data. $\underline{\text { Int }}$. J. Solids Struct. 35, 4411 (1998)

21. M. Dao, N. Chollacoop, K.J. Van Vliet, T.A. Venkatesh, and S. Suresh: Computational modeling of the forward and reverse problems in instrumented sharp indentation. Acta Mater. 49, 3899 (2001).

22. N. Chollacoop, M. Dao, and S. Suresh: Depth-sensing instrumented indentation with dual sharp indenters. Acta Mater. 51. 3713 (2003).

23. E.G. Herbert, G.M. Pharr, W.C. Oliver, B.N. Lucas, and J.L. Hay: On the measurement of stress-strain curves by spherical indentation. Thin Solid Films 398-399, 331 (2001).

24. S. Jayaraman, G.T. Hahn, W.C. Oliver, C.A. Rubin, and P.C. Bastias: Determination of monotonic stress-strain curve of hard materials from ultra-low-load indentation tests. Int. J. Solids Struct. 35, 365 (1998).

25. Y.T. Cheng and C.M. Cheng: Scaling relationships in conical indentation of elastic perfectly plastic solids. Int. J. Solids Struct. 36. 1231 (1999).

26. A.E. Giannakipoulos and S. Suresh: Determination of elastoplastic properties by instrumented sharp indentation. Scr. Mater. 40. 1191 (1999).

27. T.A. Venkatesh, K.J. Van Vliet, A.E. Giannakopoulos, and S. Suresh: Determination of elasto-plastic properties by instrumented sharp indentation: Guidelines for property extraction. Scr. Mater. 42, 833 (2000).
28. J.L. Bucaille, S. Stauss, E. Felder, and J. Michler: Determination of plastic properties of metals by instrumented indentation using different sharp indenters. Acta Mater. 51, 1663 (2003).

29. K.D. Bouzakis and N. Michailidis: Coating elastic-plastic properties determined by means of nanoindentations and FEM-supported evaluation algorithms. Thin Solid Films 469-470, 227 (2004).

30. Y.T. Cheng and C.M. Cheng: Relationships between hardness, elastic modulus, and the work of indentation. Appl. Phvs. Lett. 73, 614 (1998).

31. Y.T. Cheng and C.M. Cheng: What is indentation hardness? Surf. Coat. Technol. 133-134, 417 (2000).

32. J. Malzbendera and G. de With: Indentation load-displacement curve, plastic deformation, and energy. J.Mater. Res. 17, 502 (2002).

33. K.W. McElhaney, J.J. Vlassak, and W.D. Nix: Determination of indenter tip geometry and indentation contact area for depth-sensing indentation experiments. J. Mater. Res. 13, 1300 (1998).

34. J. Mencik and M.V. Swain: Error associated with depth sensing micro-indentation. J. Mater. Res. 10, 1491 (1995).

35. J. Alcala, A.C. Barone, and M. Anglada: The influence of plastic hardening on surface deformation modes around Vickers and spherical indents. Acta Mater. 48, 3451 (2000).

36. Y. Choi, H.S. Lee, and D. Kwon: Analysis of sharp-tip-indentation load-depth curve for contact area determination taking into account pile-up and sink-in effects. J. Mater. Res. 19, 3307 (2004).

37. Y.H. Lee, J.H. Hahn, S.H. Nahm, J.I. Jang, and D. Kwon: Investigations on indentation size effects using a pile-up corrected hardness. J. Phvs. D: Appl. Phvs. 41, 074027 (2008).

38. ISO/FDIS 14577-1: Metallic Materials_Instrumented Indentation Test for Hardness and Materials Parameters; Part 1, Test Method (International Organization for Standardization, Geneva, Switzerland, 2002).

39. ASTM E8-04: Standard Test Methods for Tension Testing of Metallic Materials (ASTM International, W. Conshohocken, PA, 2002). 